Article

\title{
Synthesis and Properties of Plasma-Polymerized Methyl Methacrylate via the Atmospheric Pressure Plasma Polymerization Technique
}

\author{
Choon-Sang Park ${ }^{1}$, Eun Young Jung ${ }^{1}$, Hyo Jun Jang ${ }^{1}$, Gyu Tae Bae ${ }^{1}$, Bhum Jae Shin ${ }^{2}$ and \\ Heung-Sik Tae ${ }^{1, *}$ \\ 1 School of Electronics Engineering, College of IT Engineering, Kyungpook National University, Daegu 41566, \\ Korea; purplepcs@ee.knu.ac.kr (C.-S.P.); eyjung@knu.ac.kr (E.Y.J.); bs00201@knu.ac.kr (H.J.J.); \\ doctor047@knu.ac.kr (G.T.B.) \\ 2 Department of Electronics Engineering, Sejong University, Seoul 05006, Korea; hahusbj@sejong.ac.kr \\ * Correspondence: hstae@ee.knu.ac.kr; Tel.: +82-53-950-6563
}

Received: 17 December 2018; Accepted: 22 February 2019; Published: 28 February 2019

\begin{abstract}
Pinhole free layers are needed in order to prevent oxygen and water from damaging flexible electrical and bio-devices. Although polymerized methyl methacrylate (polymethyl methacrylate, PMMA) for the pinhole free layer has been studied extensively in the past, little work has been done on synthesizing films of this material using atmospheric pressure plasma-assisted electro-polymerization. Herein, we report the synthesis and properties of plasma-PMMA (pPMMA) synthesized using the atmospheric pressure plasma-assisted electro-polymerization technique at room temperature. According to the Fourier transform infrared spectroscopy (FT-IR), X-ray photoelectron spectroscopy (XPS), and time of flight-secondary ion mass spectrometry (ToF-SIMS) results, the characteristic peaks from the pPMMA polymer chain were shown to have been detected. The results indicate that the percentage of hydrophobic groups $(\mathrm{C}-\mathrm{C}$ and $\mathrm{C}-\mathrm{H})$ is greater than that of hydrophilic groups $(\mathrm{C}-\mathrm{O}$ and $\mathrm{O}-\mathrm{C}=\mathrm{O}$ ). The field emission-scanning electron microscope (FE-SEM) and thickness measurement results show that the surface morphology is quite homogenous and amorphous in nature, and the newly proposed pPMMA film at a thickness of $1.5 \mu \mathrm{m}$ has high transmittance (about 93\%) characteristics. In addition, the results of water contact angle tests show that pPMMA thin films can improve the hydrophobicity.
\end{abstract}

Keywords: methyl methacrylate; encapsulation; atmospheric pressure plasma; plasma polymerization; plasma-polymerized methyl methacrylate (pPMMA); time of flight-secondary ion mass spectrometry (ToF-SIMS); hydrophobicity

\section{Introduction}

Plasma-assisted electro-polymerization is a new research field on the interaction of plasma with monomer and electrolyte solution, and it uses plasma to drive the chemical reactions [1-6]. Electrochemically controlled formation of thin polymer films using plasma is one of the feasible routes to design new functional polymer materials. The creation of new polymer materials would require novel technological developments. Recently, there have been a number of interesting reports concerning an aerosol-through-plasma (ATP) technique for generating particulate materials [7-14]. In brief, this technology consists of passing aerosols through various plasma systems, particularly radio frequency (RF) and microwave, to create particulates, nanoparticles, and thin films. Among various plasma systems, by using a nonthermal atmospheric pressure plasma (APP) as a gaseous electrode, plasma-assisted electro-polymerization has attracted increasing attention in the green synthesis of polymer thin films and nanomaterials. Thanks to the low-temperature and cost-effective dry process, 
the APP polymerization process is a promising growth method for synthesizing polymer thin films with functional features, therefore being well-suited for versatile substrates and applications. The APP polymerization process can obtain high-quality polymer films and nanoparticles, with easily controllable deposition rate, size, and is well-suited for a wide range of substrates. Furthermore, APP reactors do not require a vacuum atmosphere and special equipment. In spite of intensive studies, only a few groups have reported successful plasma polymerization using APP [15-25]. Our previous works recently reported the stationary APP jets (APPJs) polymerization employing the new types of impinging technique and ATP system [26-30]. When discharge is initiated, the flowing inert argon gas can inject electrons and ions into the vaporized monomer bubbles. This impinging technique and ATP system increase the charged particles and density by means of plasmas in the monomer fragmentation (or nucleation) and recombination regions. In this case, the polymer films can have different properties depending on the types of precursors and plasma conditions. Consequently, the advanced plasma-based process for synthesizing new materials including polymers requires a deeper understanding of plasma-assisted electro-polymerization.

Recently, polymerized methyl methacrylate (polymethyl methacrylate, PMMA) having pinhole free characteristics has been widely used as organic thin films, encapsulations, biosensors, and electronics materials [21-25,31-36]. The plasma polymerizations of porous conducting polymers, such as aniline, pyrrole, and thiophene, have been successfully implemented using our APP polymerization technique [26-30]. However, there is no report on the synthesis of plasma-PMMA (pPMMA) with pinhole free and nonporous characteristics as a dielectric polymer through plasma-assisted electro-polymerization with the novel APP polymerization technique. Accordingly, this study uses Fourier transform-infrared spectroscopy (FT-IR), X-ray photoelectron spectroscopy (XPS), time of flight-secondary ion mass spectrometry (ToF-SIMS), field emission-scanning electron microscopy (FE-SEM), and transmittance measurement to analyze newly proposed pPMMA film synthesized by APPJs polymerization. The resultant surface wettability is also investigated.

\section{Experimental and Characterizations}

\subsection{Atmospheric Pressure Plasma Synthesis and Materials}

A stationary atmospheric pressure plasma (APP) polymerization technique by using liquid monomer was conducted by an APP jets (APPJs) and aerosol-through-plasma system mentioned in our previous work [26]. In the previous work, a newly proposed guide tube and a bluff body with impinging jet systems were introduced to suppress the quenching phenomenon from ambient air, thereby increasing the charged particles and plasma energies in the nucleation area [27]. In the case of conventional APPJs without the proposed guide tube and buff body, the plasma was only produced within the area of the three array jets because of the directional characteristics of the streamer-like discharges. In the case of the newly proposed guide tube and bluff body with impinging jet systems, the plasma produced in the impinging region was changed to a broadened glow-like discharge, thereby increasing the plasma region about 60 -fold and the deposition area [27,29]. The proposed APPJs with impinging technique and ATP system can produce a broadened and intense plasma discharge with large area deposition and obtain high-quality polymers, with easily controllable morphology, deposition rate, deposition size, and is well-suited for a wide range of substrates. The detailed APP polymerization system, featuring the guide tube and bluff body, employed in this work, was described in the references of [26-30]. In the case of a low gas flow rate below 2500 standard cubic centimeters per minute $(\mathrm{sccm})$ for the main discharge gas and below $300 \mathrm{sccm}$ for vaporizing or carrier monomer gas flow rates, intense or stable or broadened plasma was not produced even though the proposed guide tube and bluff body with impinging jet systems was used [29]. In this experiment, therefore, the argon (Ar) gas was the main plasma discharge gas where its purity was high $(99.999 \%)$ and its flow rate was fixed at $2500 \mathrm{sccm}$. Further Ar gas was supplied to the glass bubbler for vaporizing the liquid methyl methacrylate (MMA) monomer (Sigma-Aldrich Co., St. Louis, MO, USA, $M_{w}=100 \mathrm{~g} \cdot \mathrm{mol}^{-1}$ ) 
at a fixed flow rate of $300 \mathrm{sccm}$. For plasma generation, a sinusoidal voltage with a peak value of $12 \mathrm{kV}$ and a frequency of $30 \mathrm{kHz}$ were fixed and applied to the proposed APP polymerization device. The used substrates were glasses and polyethylene terephthalates (PETs). The pPMMA was directly deposited on substrates at room temperature by the novel APP polymerization technique. During the APP polymerization experiments, the plasma jet was not moved, and the as such experiments were conducted in stationary deposition.

\subsection{Fourier Transform-Infrared Spectroscopy Analysis}

The Fourier transform infrared spectra (FT-IR) were used to determine the chemical changes of pPMMA introduced by the APP and measured on a Perkin-Elmer Frontier spectrometer (PerkinElmer, Waltham, MA, USA) between 650 and $4000 \mathrm{~cm}^{-1}$.

\subsection{X-ray Photoelectron Spectroscopy Analysis}

An X-ray photoelectron spectroscopy (XPS) (ESCALAB 250XI surface analysis system, Thermo Fisher Scientific, Waltham, MA, USA) was used to investigate the surface chemical compositions and atomic concentration of the pPMMA films. In the XPS measurement, the voltage and current of the monochromatic Al K $\alpha$ X-ray source $(\mathrm{hv}=1486.7 \mathrm{eV})$ were $15 \mathrm{kV}$ and $20 \mathrm{~mA}$, respectively. The measurement angle was $60^{\circ}$ and the measurement depth estimated to range from 8 to $10 \mathrm{~nm}$. The measurement area was $500 \mu \mathrm{m} \times 500 \mu \mathrm{m}$ and the pressure was about $10^{-8} \mathrm{~Pa}$. The $\mathrm{C} 1 \mathrm{~s}$ spectrum $(285.0 \mathrm{eV})$ was used to calibrate the energy scale. Elements present on the deposited surfaces were identified from XPS survey scans and quantified with Thermo Avantage software (v.5.977, Waltham, MA, USA) using a Shirley background and applying the relative sensitivity factors provided by the manufacturer of the instrument. The relative sensitivity factors of $C 1$ s and $O$ 1s were 1.0 and 2.8 , respectively. For high-resolution spectra, the constant analyzer energy modes were used at $200 \mathrm{eV}$ for the survey scan and $50 \mathrm{eV}$ pass energy for the element scan, respectively. Since the pPMMA samples and substrates were insulators, we used an additional electron gun to allow for surface neutralization to adjust the charge compensation during the measurements. To curve fit the high-resolution $C 1$ s and $\mathrm{O} 1$ s peaks, the deconvolution of $\mathrm{C} 1 \mathrm{~s}$ and $\mathrm{O} 1$ s peaks was analyzed by the Thermo Avantage software. The peaks were deconvoluted using Gaussian-Lorentzian peak shapes (constrained between $80 \%$ and $100 \%$ Gaussian) and the full-width at half maximum (FWHM) of each line shape was constrained between 2.0 and $3.0 \mathrm{eV}$.

\subsection{Time of Flight-Secondary Ion Mass Spectrometry Analysis}

The surface structure and composition of the pPMMA films were examined by the time of flight-secondary ion mass spectrometry (ToF-SIMS) V instrument (ION-TOF GmbH, Munster, Germany) with a bismuth primary-ion $\left(\mathrm{Bi}_{3}{ }^{+}\right)$gun source. The pressure in the ToF-SIMS chamber was maintained at less than $1 \times 10^{-9}$ Torr. $\mathrm{Bi}_{3}{ }^{+}(0.5 \mathrm{pA})$ accelerated at $30 \mathrm{keV}$ was used as the analysis (primary) gun. The negative-ion and positive-ion mass spectra of a $500 \mu \mathrm{m} \times 500 \mu \mathrm{m}$ area were acquired at $\mathrm{Bi}_{3}{ }^{+}$primary-ion beam of $30 \mathrm{keV}$. For a more accurate mass scale of pPMMA film, the spectra were calibrated based on the characteristic pPMMA ion, $\mathrm{C}_{4} \mathrm{H}_{5} \mathrm{O}_{2}{ }^{-}$including the known $\mathrm{CH}^{-}$ and $\mathrm{C}_{4} \mathrm{H}^{-}$ions.

\subsection{Surface Morphology Study}

The surface morphology of the pPMMA films on the glass substrates was characterized using a field emission-scanning electron microscope (FE-SEM) (Hitachi SU8220, Hitachi, Tokyo, Japan) with accelerating voltage and current of 3 or $5 \mathrm{kV}$ and $10 \mathrm{~mA}$, respectively. The samples for FE-SEM were conductive platinum-coated before loading into the chamber. 


\subsection{Thickness Measurement}

The thickness of pPMMA was determined using a KLA Tencor P-7 stylus profilometer (Milpitas, CA, USA) with a diamond probe having a radius of $2 \mu \mathrm{m}$.

\subsection{Optical Transmittance}

The optical transmittance (or transmission) of pPMMA film was performed on a glass substrate followed by measurement of its transmission by using of UV-Vis spectrophotometer (Cary 5G, Varian). The spectrum ranged from 300 to $800 \mathrm{~nm}$ with a scanning step of $0.5 \mathrm{~nm}$. Glass and PET plates were used as reference. The pPMMA samples were used for measurement of optical transmittance and the results were expressed as a mean value.

\subsection{Water Contact Angle Measurements}

The sessile drop method using Drop Shape Analyzers (KRUSS, DSA100, Germany) was used to measure the surface wettability of the pPMMA films grown on the glass and PET substrates. After the ultrapure water droplet contacted the sample surfaces, the contact angles were measured by the built-in charge-coupled device (CCD) video camera with the software provided by the manufacturer. The average value of the contact angle was taken after five measurements for each sample.

\section{Results and Discussion}

The FT-IR absorption spectrum of the newly proposed pPMMA film grown on glass substrate when using the APP polymerization technique after 90 min deposition is shown in Figure 1. Bands from 3000 to $3600 \mathrm{~cm}^{-1}$ of the $\mathrm{OH}$ bonding group, implying oxidation of the particles induced by quenching from ambient air, were not observed thanks to using the newly proposed guide tube and bluff body systems. The FT-IR spectra of the PPMMA polymer were found to exhibit absorption bands at 2989 and $2951 \mathrm{~cm}^{-1}$. These bands were caused by $-\mathrm{CH}_{3}$ asymmetric stretching. A sharp band located at $1731 \mathrm{~cm}^{-1}$ was ascribed to the carbonyl group. The pPMMA showed an IR absorption band at $1433 \mathrm{~cm}^{-1}$ due to the asymmetric bending vibration $\left(\mathrm{CH}_{3}\right)$ of the methyl group. The peak at $1381 \mathrm{~cm}^{-1}$ was attributed to $\mathrm{OCH}_{3}$ deformation of pPMMA. The characteristic absorption bands at 1265 and $1145 \mathrm{~cm}^{-1}$ respectively correspond to $\mathrm{C}-\mathrm{O}-\mathrm{C}$ stretching and the $\mathrm{C}-\mathrm{O}$ group of pristine PMMA polymer. The band at $1193 \mathrm{~cm}^{-1}$ was due to $-\mathrm{OCH}_{3}$ stretching. The absorption bands at 977 and $716 \mathrm{~cm}^{-1}$ were assigned to the $\mathrm{CH}_{2}$ wagging and rocking modes of PPMMA, respectively [37-40].

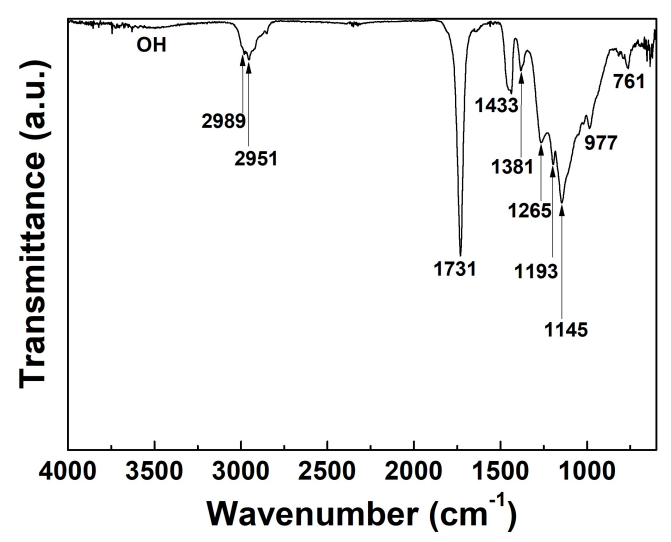

Figure 1. Fourier transform infrared spectroscopy (FT-IR) spectra of plasma-polymerized methyl methacrylate (pPMMA) thin films grown on a glass substrate when using the proposed atmospheric pressure plasma (APP) polymerization technique after 90 min deposition.

The XPS survey spectra, with elemental composition percent (Figure 2a, insets) of the atomic distribution and detailed high-resolutions of $\mathrm{C} 1 \mathrm{~s}$ and $\mathrm{O}$ 1s spectra in the newly proposed pPMMA 
thin films grown on glass substrate when using the APP polymerization technique after 90 min deposition, are shown in Figure 2. The element content was calculated by the ratio of the corresponding integral area of the peaks. The XPS survey spectra in Figure $2 \mathrm{a}$ are typically observed in the signals corresponding to $\mathrm{C} 1 \mathrm{~s}(285.0 \mathrm{eV})$ and $\mathrm{O} 1 \mathrm{~s}(531.0 \mathrm{eV})$ electronic orbitals of pPMMA [41,42]. The $\mathrm{C}$ and $\mathrm{O}$ atoms belong to the MMA monomer structure. To get further insight into the types and ratios of the surface functional groups of the PPMMA, the curve fitting of the high-resolution $\mathrm{C}$ 1s and $\mathrm{O}$ 1s peaks was analyzed by the XPS peak. The assignments of the fitted components and the compositions of the $\mathrm{C} 1 \mathrm{~s}$ and $\mathrm{O} 1 \mathrm{~s}$ levels are summarized in Table 1 . The $\mathrm{C}$ 1s peaks of pPMMA were decomposed by curve fitting into three components; the component at $285.0 \mathrm{eV}$ corresponding to $\mathrm{C}-\mathrm{C}$ and $\mathrm{C}-\mathrm{H}$ bonds, the component at $286.8 \mathrm{eV}$ corresponding to $\mathrm{C}-\mathrm{O}$ bands, and the component at $289.1 \mathrm{eV}$ corresponding to $\mathrm{O}-\mathrm{C}=\mathrm{O}$ bonds. The $\mathrm{O}$ 1s peaks of pPMMA can be divided into two component peaks, which respectively indicate two oxygen-containing groups; $\mathrm{C}=\mathrm{O}(531.0 \mathrm{eV})$ and $\mathrm{C}-\mathrm{O}(533.2 \mathrm{eV})$. After fitting the relative intensities of the two peaks, the peak corresponding to the $\mathrm{C}=\mathrm{O}$ group was shown to be higher than the one of the $\mathrm{C}-\mathrm{O}$ group in Figure 2c. Comparing the $\mathrm{C} 1 \mathrm{~s}$ spectra, the relative intensities of the $\mathrm{C}-\mathrm{O}$ and $\mathrm{O}-\mathrm{C}=\mathrm{O}$ groups were lower, while the relative intensities of the $\mathrm{C}-\mathrm{C}$ and $\mathrm{C}-\mathrm{H}$ groups in the same spectra were higher in Figure $2 \mathrm{~b}$. The high peak could be attributed to cross-linking reactions and the formation of new $\mathrm{C}-\mathrm{C}$ bonds. The values in Table 1 denote the ratio of carbon atoms in the hydrophobic groups $(\mathrm{C}-\mathrm{C}$ and $\mathrm{C}-\mathrm{H})$ to those in the hydrophilic groups $(\mathrm{C}-\mathrm{O}$ and $\mathrm{O}-\mathrm{C}=\mathrm{O})$ on the surface. The results indicate that the percentage of hydrophobic groups is greater than that of hydrophilic groups. This means that our pPMMA surface becomes carbon-rich and eventually it is expected to increase the water contact angles (WCAs) after pPMMA coating [41,42].

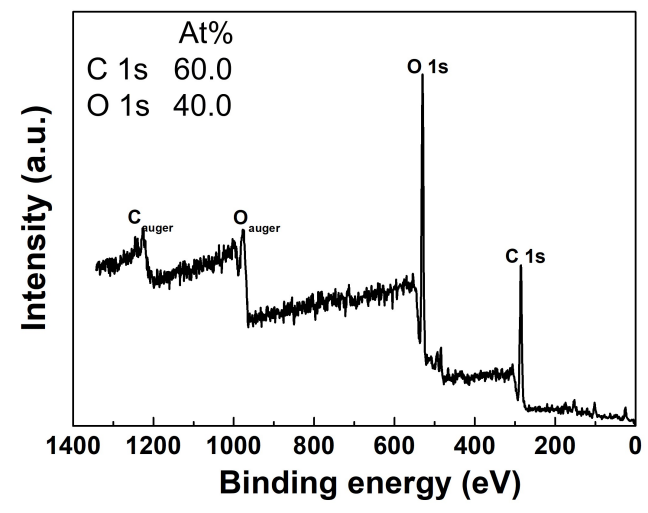

(a)

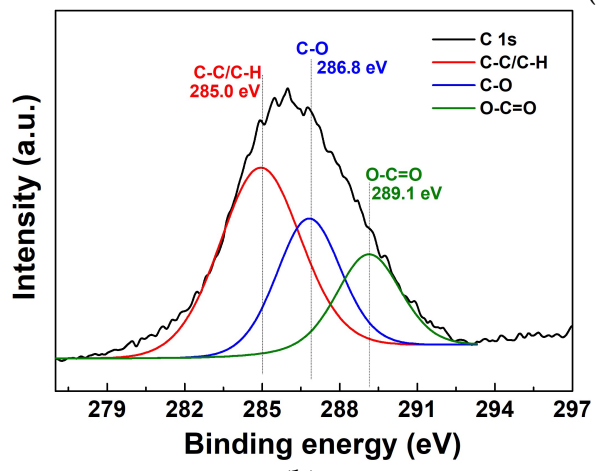

(b)

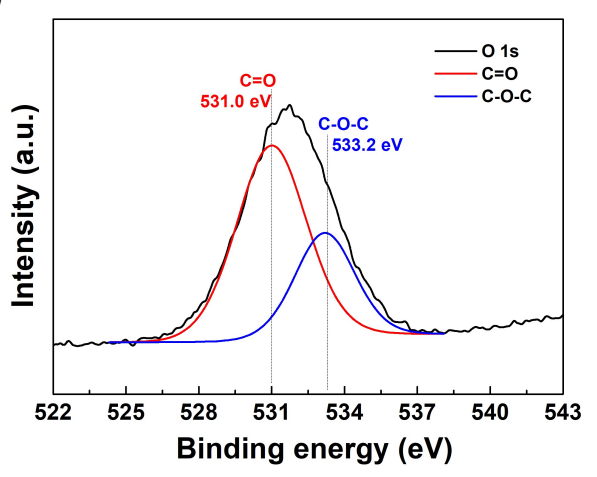

(c)

Figure 2. (a) X-ray photoelectron spectroscopy (XPS) survey spectra, detailed high-resolution with deconvolutions of (b) C 1s, and (c) O 1s spectra of pPMMA thin films grown on a glass substrate when using the proposed APP polymerization technique after 90 min deposition. Insets in (a) represent the atom percent in the PPMMA film. 
Table 1. The contents of functional groups of $\mathrm{C} 1 \mathrm{~s}$ and $\mathrm{O} 1 \mathrm{~s}$ core level spectra of plasma-polymerized methyl methacrylate (pPMMA) film observed in the XPS spectra of Figure 2b,c.

\begin{tabular}{cccccc}
\hline \multirow{2}{*}{ Sample } & \multicolumn{4}{c}{ Concentrations of Correlative Functional Group (\%) } \\
\cline { 2 - 6 } & \multicolumn{3}{c}{ C 1s } & \multicolumn{3}{c}{ O 1s } \\
\cline { 2 - 6 } & C-C/C-H (285.0 eV) & C-O (286.8 eV) & O-C=O (289.1 eV) & C=O (531.0 eV) & C-O (533.2 eV) \\
\hline pPMMA & 54.9 & 29.4 & 15.7 & 68.9 & 31.1 \\
\hline
\end{tabular}

The pPMMA films were characterized in both negative- and positive-ion modes using the ToF-SIMS method in order to determine the specific structures. The negative-ion and positive-ion spectra (0-200 amu) of ToF-SIMS on the surface of the newly proposed pPMMA thin films grown on a glass substrate when using the proposed APP polymerization technique after 90 min deposition are shown in Figure 3. As shown in Figure 3a using negative-ion mode, the ions at $m / z=31,55,71$, 85, 141 , and 185 were assigned to $\mathrm{CH}_{3} \mathrm{O}^{-}, \mathrm{C}_{3} \mathrm{H}_{3} \mathrm{O}^{-}, \mathrm{C}_{3} \mathrm{H}_{3} \mathrm{O}_{2}{ }^{-}, \mathrm{C}_{4} \mathrm{H}_{5} \mathrm{O}_{2}{ }^{-}, \mathrm{C}_{8} \mathrm{H}_{13} \mathrm{O}_{2}{ }^{-}$, and $\mathrm{C}_{9} \mathrm{H}_{13} \mathrm{O}_{4}{ }^{-}$, respectively [43-46]. These fragment ions arose from the pPMMA chains. The most abundant fragment ions were $\mathrm{CH}_{3} \mathrm{O}^{-}$and $\mathrm{C}_{4} \mathrm{H}_{5} \mathrm{O}_{2}{ }^{-}$, which were the monomer where the methyl group $\left(\mathrm{CH}_{3}\right)$ was removed from the ether linkage $\left(\mathrm{H}_{3} \mathrm{C}-\mathrm{O}-\mathrm{C}\right)[44,45]$. The small negative hydroxyl ion $\mathrm{OH}^{-}(\mathrm{m} / z=17)$ implying the oxidation of the pPMMA thin films induced by quenching from ambient air was observed thanks to using the proposed guide tube and bluff body with impinging jet systems. As shown in Figure $3 \mathrm{~b}$ using the positive-ion mode, some characteristic peaks from the pPMMA polymer chain were detected. The ions at $m / z=15,27,31,39,41,55,59,69,77$, and 91 were assigned to $\mathrm{CH}_{3}{ }^{+}, \mathrm{C}_{2} \mathrm{H}_{3}{ }^{+}$, $\mathrm{CH}_{3} \mathrm{O}^{+}, \mathrm{C}_{3} \mathrm{H}_{3}{ }^{+}, \mathrm{C}_{3} \mathrm{H}_{5}{ }^{+}, \mathrm{C}_{4} \mathrm{H}_{7}{ }^{+}, \mathrm{C}_{2} \mathrm{H}_{3} \mathrm{O}_{2}{ }^{+}, \mathrm{C}_{4} \mathrm{H}_{5} \mathrm{O}^{+}, \mathrm{C}_{6} \mathrm{H}_{5}{ }^{+}$, and $\mathrm{C}_{7} \mathrm{H}_{7}{ }^{+}$, respectively. These fragment ions also originated from the pPMMA chains.

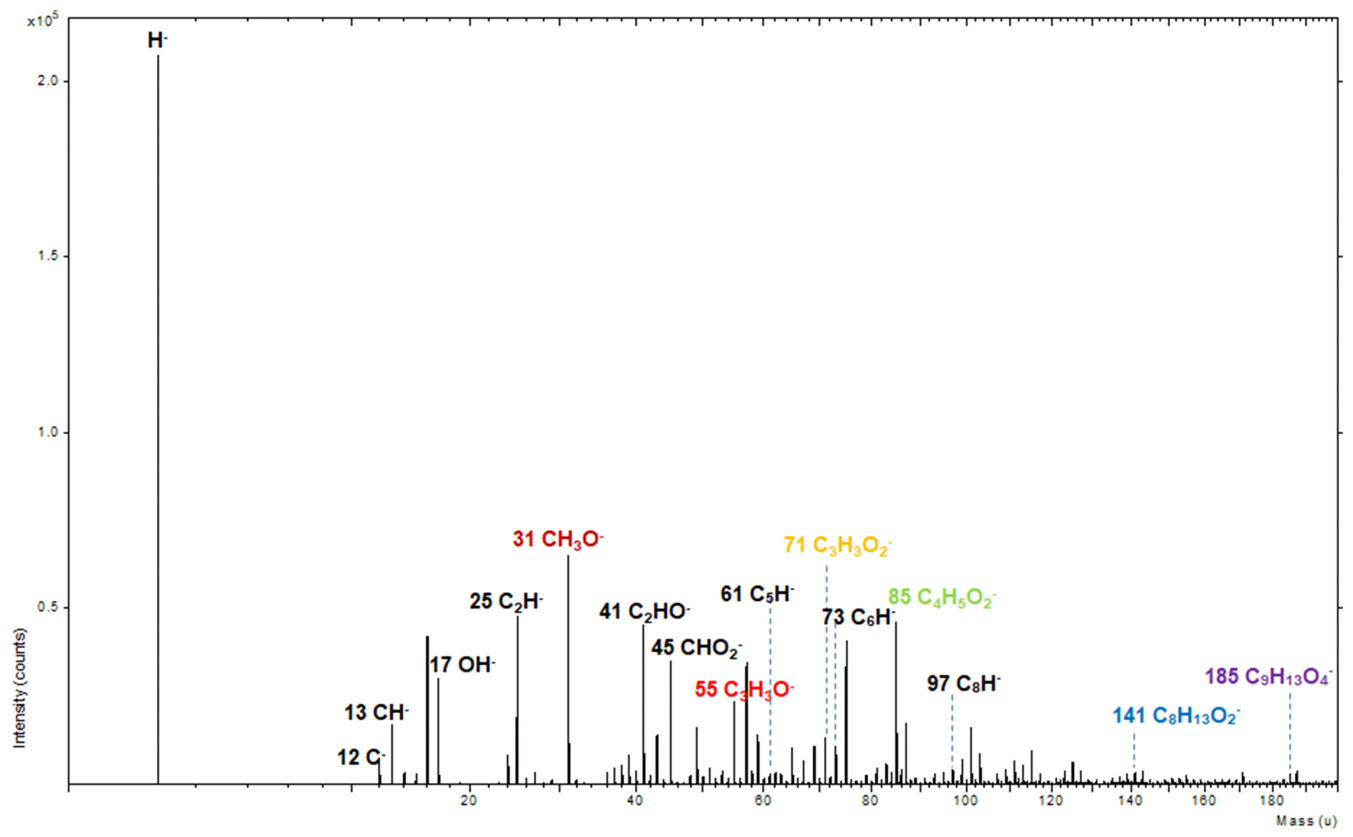

(a)

Figure 3. Cont. 


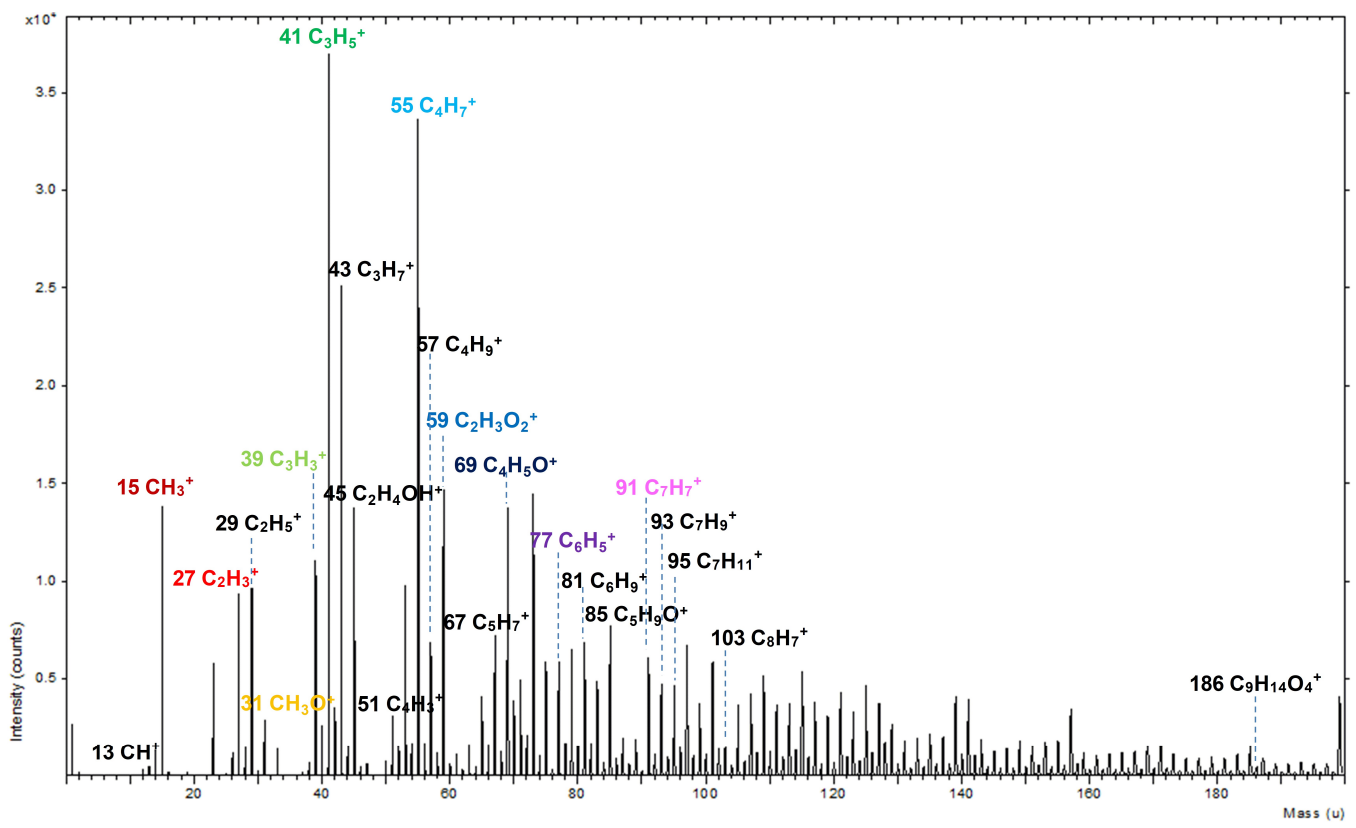

(b)

Figure 3. (a) Negative-ion and (b) positive-ion spectra (0-200 amu) of time of flight-secondary ion mass spectrometry (ToF-SIMS) on the surface of pPMMA thin films grown on a glass substrate when using the proposed APP polymerization technique after 90 min deposition.

The characteristics of the conductor or semiconductor layer can be influenced by the surface morphology of the coated dielectric layer [47,48]. In this sense, the plane and cross-sectional view SEM images of the newly proposed pPMMA thin films grown on glass substrates when using the proposed APP polymerization technique after $90 \mathrm{~min}$ deposition are displayed in Figure 4 . As shown by the SEM results of Figure 4, the pPMMA film had a deposition rate of about $0.023 \mu \mathrm{m} \cdot \mathrm{min}^{-1}$, and had no pits and pinholes. The surface of the pPMMA film was observed to be homogeneous, amorphous, and smooth, which is considered to be one of the most important features of the dielectric layer required in organic thin films, encapsulations, biosensors, and electronics applications. The SEM images of Figure 4 illustrating the pPMMA films with the self-assembled mesoscopic structure, confirm that the proposed plasma-assisted electro-polymerization technique enables large-area fabrication of mesoscopic structured pPMMA films.

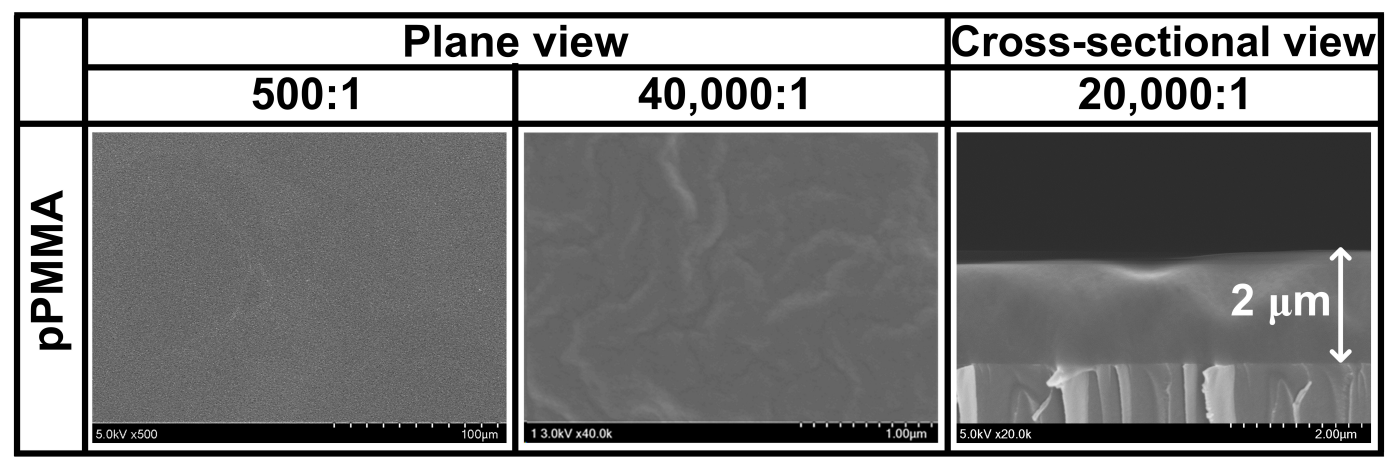

Figure 4. Plane and cross-sectional views of scanning electron microscopy (SEM) images of pPMMA thin films grown on a glass substrate when using the proposed APP polymerization technique after 90 min deposition.

The variation in the film thickness of the newly proposed pPMMA thin films grown on glass substrates when using the proposed APP polymerization technique at different deposition times is 
shown in Figure 5. Under various deposition times, the deposition rates were about $0.025 \mu \mathrm{m} \cdot \mathrm{min}^{-1}$ for $60 \mathrm{~min}$ deposition time and about $0.023 \mu \mathrm{m} \cdot \mathrm{min}^{-1}$ for $90 \mathrm{~min}$ deposition time, which was estimated to be low. However, the deposition rates were increased significantly and maintained after $120 \mathrm{~min}$ deposition time at about $0.036 \mu \mathrm{m} \cdot \mathrm{min}^{-1}$ in the proposed APP polymerization technique. This means that the deposition rates in our APP polymerization system remain almost constant after 120 min deposition time.

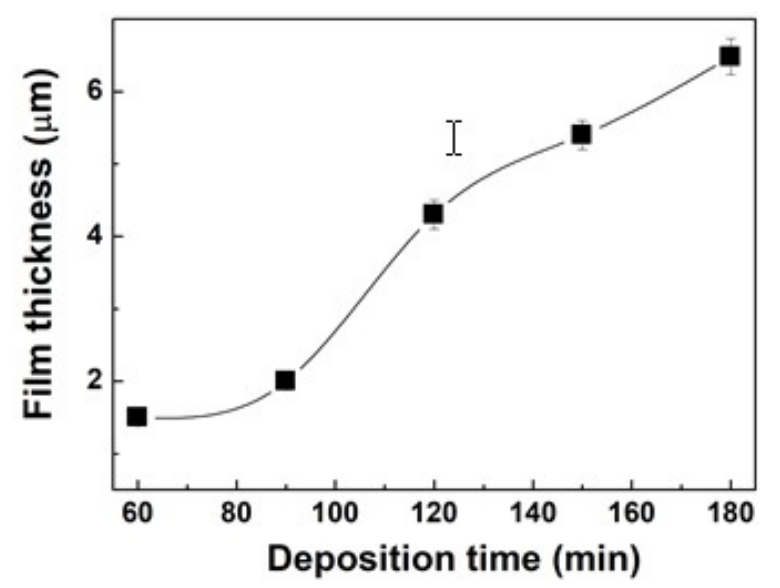

Figure 5. Variation in the film thickness of pPMMA thin films grown on glass substrates when using the proposed APP polymerization technique at different deposition times.

The optical transmittance of pPMMA plays an important role when used as optical material. Therefore, the variation in the optical transmittance (or transmission) of the newly proposed pPMMA thin films grown on glass substrates when using the proposed APP polymerization technique at different deposition times is shown in Figure 6. The pPMMA thin film had a high transparency within the range of visible wavelength $(400-700 \mathrm{~nm})$, which could reach up to $93 \%$ at $600 \mathrm{~nm}$. As the deposition times were increased, the corresponding transmittances decreased slightly.

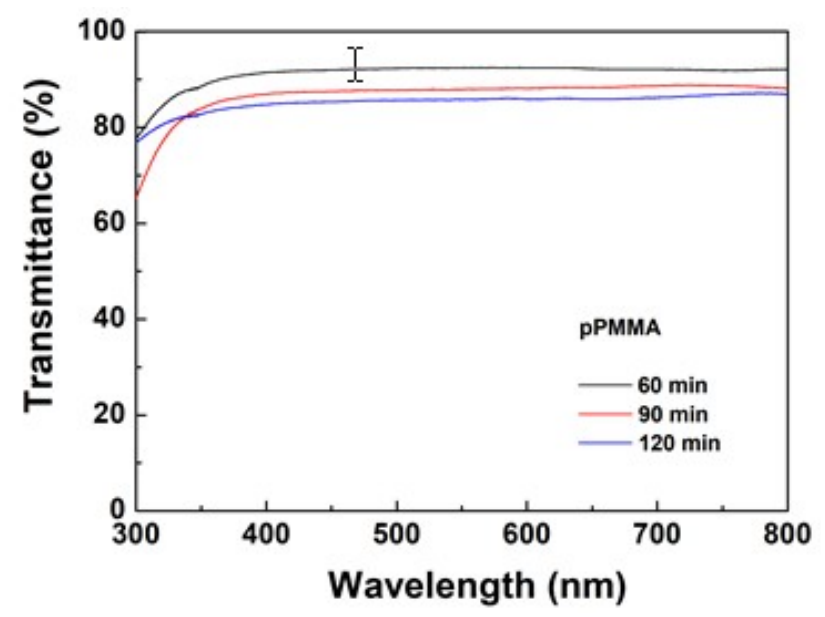

Figure 6. Variation in the optical transmittance (or transmission) of pPMMA thin films grown on glass substrates when using the proposed APP polymerization technique at different deposition times.

To calculate the surface wettability or hydrophobicity of the newly proposed polymer, the WCAs of pPMMA were measured [43,47-49]. The WCAs analysis is a simple, rapid, and direct method to evaluate the hydrophobic or hydrophilic feature of a surface. The variation in the WCAs on the pristine (bare) substrates and pPMMA thin films grown on glass and polyethylene terephthalate (PET) substrates when using the proposed APP polymerization technique after 90 min deposition is shown 
in Figure 7. From Figure 7, after deposition, we can see that the WCAs of the pPMMA thin films gradually increased for both glass and PET substrates. The results of the WCA tests showed that the pPMMA thin films could increase the WCAs after deposition. The increased WCAs of the pPMMA thin films were presumably due to the cleavage of the hydrophilic groups and the newly formed hydrophobic groups $(\mathrm{C}-\mathrm{C}$ and $\mathrm{C}-\mathrm{H})$. In addition, we observed a change in the WCAs depending on the substrates. The surface roughness (root mean square roughness, $\mathrm{R}_{\mathrm{q}}$ ) of the pPMMA thin films on the glass substrate was $25.9 \mathrm{~nm}$, whereas the $\mathrm{R}_{\mathrm{q}}$ of the pPMMA thin films on the PET substrate was $0.6 \mathrm{~nm}$ in Figure S1 and Table S1. The WCA of the glass sample decreased as the $\mathrm{R}_{\mathrm{q}}$ was increased. The changed WCAs of the pPMMA thin films on both glass and PET substrates were due to the differences in the surface roughness [50,51]. It is a typical phenomenon that appears on hydrophilic surfaces depending on the Wenzel theory [52]. The detailed atomic force microscope images and the $\mathrm{R}_{\mathrm{q}}$ of the pPMMA thin films surface grown on glass and PET substrates are shown in Figure S1 and Table S1.

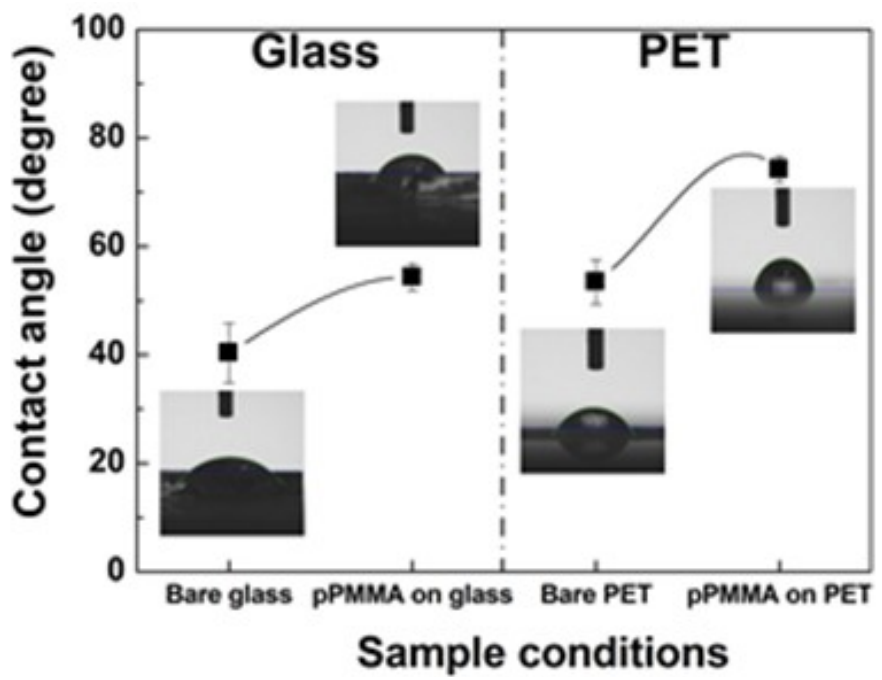

Figure 7. Variation in the water contact angles (WCAs) on the pristine (bare) substrates and pPMMA thin films grown on glass and polyethylene terephthalate (PET) substrates when using the proposed APP polymerization technique after 90 min deposition. Insets represent photographs of the water droplets on the pristine and pPMMA film.

\section{Conclusions}

In this work, we used for the first-time APP polymerization techniques to provide further insight into the process of electro-polymerization of MMA monomer. The pPMMA thin films were successfully obtained by the atmospheric pressure plasma-assisted electro-polymerization technique. The experimental results show that the newly proposed pPMMA has quite homogenous, amorphous, pinhole free, and high transmittance characteristics. In addition, the results of the water contact angle tests show that the pPMMA thin films can improve the hydrophobicity. The plasma-assisted electro-polymerization technique presented in this study is very simple, highly reproducible, and permits fabrication of large areas of mesoscopic structured films having potential as membranes, organic, inorganic materials, and photonic molecules.

Supplementary Materials: The following are available online at http:/ /www.mdpi.com/2073-4360/11/3/396/s1, Figure S1: Two- (2D) and three-dimensional (3D) AFM images of pPMMA film surfaces grown on glass and PET substrates when using the proposed APP polymerization technique after 90 min deposition, Table S1: Root mean square roughness $\left(R_{q}\right)$ and average roughness $\left(R_{a}\right)$ obtained from AFM images of pPMMA film surfaces grown on glass and PET substrates when using the proposed APP polymerization technique after 90 min deposition.

Author Contributions: C.-S.P., E.Y.J., and H.-S.T. conceived and designed the study; C.-S.P., E.Y.J., H.J.J., and G.T.B. performed the experiments; C.-S.P. and E.Y.J. contributed analysis tools; C.-S.P., E.Y.J., and H.-S.T. analyzed the data; C.-S.P. and H.-S.T. wrote the majority of the paper and all authors reviewed and approved the final version. 
Funding: This research was funded by the National Research Foundation of Korea (NRF) grant funded by the Korea government (MOE) (No. 2018R1D1A1B07046640) and Korea government (MOE) (No. 2016R1D1A1B03933162).

Acknowledgments: Authors would like to thank Sang-Geul Lee and Weon-Sik Chae at the Korea Basic Science Institute (Daegu) for useful discussion and providing the FTIR data.

Conflicts of Interest: The authors declare no conflict of interest.

\section{References}

1. Koizumi, Y.; Shida, N.; Ohira, M.; Nishiyama, H.; Tomita, I.; Inagi, S. Electropolymerization on wireless electrodes towards conducting polymer microfibre networks. Nat. Commun. 2016, 7, 10404. [CrossRef] [PubMed]

2. Berkes, B.B.; Bandarenka, A.S.; Inzelt, G. Electropolymerization: Further insight into the formation of conducting polyindole thin films. J. Phys. Chem. C 2015, 119, 1996-2003. [CrossRef]

3. Thanh, D.V.; Li, L.-J.; Chu, C.-W.; Yen, P.-J.; Wei, K.-H. Plasma-assisted electrochemical exfoliation of graphite for rapid production of graphene sheets. RSC Adv. 2014, 4, 6946-6949. [CrossRef]

4. Kareem, A.T.; Kaliani, A.A. ZnS nanoparticle synthesis and stability of 1-butyl-3-methylimidazolium tetrafluoroborate ([BMIM][BF4]) under glow discharge plasma. Ionics 2013, 19, 1559-1565. [CrossRef]

5. Rogov, A.B.; Yerokhin, A.; Matthews, A. The role of cathodic current in plasma electrolytic oxidation of aluminum: Phenomenological concepts of the "soft sparking" mode. Langmuir 2017, 33, 11059-11069. [CrossRef] [PubMed]

6. Wang, Z.; Xu, C.; Lu, Y.; Wei, G.; Ye, G.; Sun, T.; Chen, J. Microplasma-assisted rapid, chemical oxidant-free and controllable polymerization of dopamine for surface modification. Polym. Chem. 2017, 8, 4388-4392. [CrossRef]

7. Phillips, J.; Luhrs, C.; Richard, M. Review: Engineering particles using the aerosol-through-plasma method. IEEE Trans. Plasma Sci. 2009, 37, 726-739. [CrossRef]

8. Luhrs, C.; Phillips, J.; Fanson, P.T. Production of unique structures using the Aerosol-Through-Plasma (A-T-P) process. WIT Trans. Built Environ. 2008, 97, 63-70.

9. Huang, T.-S.; Su, Y.-K.; Wang, P.-C. Study of organic thin film transistor with polymethylmethacrylate as a dielectric layer. Appl. Phys. Lett. 2007, 91, 092116. [CrossRef]

10. Yáñez-Pacios, A.J.; Martín-Martínez, J.M. Comparative adhesion, ageing resistance, and surface properties of wood plastic composite treated with low pressure plasma and atmospheric pressure plasma jet. Polymers 2018, 10, 643. [CrossRef]

11. Chang, C.-K.; Wang, H.-M.D.; Lan, J.C.-W. Investigation and characterization of plasma-treated poly(3-hydroxybutyrate) and poly(3-hydroxybutyrateco-3-hydroxyvalerate) biopolymers for an in vitro cellular study of mouse adipose-derived stem cells. Polymers 2018, 10, 355. [CrossRef]

12. Kan, C.-W.; Man, W.-S. Parametric study of effects of atmospheric pressure plasma treatment on the wettability of cotton fabric. Polymers 2018, 10, 233. [CrossRef]

13. Chen, K.-S.; Chang, S.-J.; Feng, C.-K.; Lin, W.-L.; Liao, S.-C. Plasma deposition and UV light induced surface grafting polymerization of NIPAAm on stainless steel for enhancing corrosion resistance and its drug delivery property. Polymers 2018, 10, 1009. [CrossRef]

14. Lin, F.; Li, W.; Tang, Y.; Shao, H.; Su, C.; Jiang, J.; Chen, N. High-performance polyimide filaments and composites improved by $\mathrm{O}_{2}$ plasma treatment. Polymers 2018, 10, 695. [CrossRef]

15. Deynse, A.V.; Cools, P.; Leys, C.; Geyter, N.D.; Morent, R. Surface activation of polyethylene with an argon atmospheric pressure plasma jet: Influence of applied power and flow rate. Appl. Surf. Sci. 2015, 328, 269-278. [CrossRef]

16. Cools, P.; Sainz-Garcı, E.; Geyter, N.D.; Nikiforov, A.; Blajan, M.; Shimizu, K.; Alba-Elıas, F.; Leys, C.; Morent, R. Influence of DBD inlet geometry on the homogeneity of plasma-polymerized acrylic acid films: The use of a microplasma-electrode inlet configuration. Plasma Process. Polym. 2015, 12, 1153-1163. [CrossRef]

17. Vrekhema, S.V.; Cools, P.; Declercq, H.; Tongel, A.V.; Vercruysse, C.; Cornelissen, M.; Geyter, N.D.; Morent, R. Application of atmospheric pressure plasma on polyethylene for increased prosthesis adhesion. Thin Solid Films 2015, 596, 256-263. [CrossRef] 
18. Morent, R.; Geyter, N.D.; Trentesaux, M.; Gengembre, L.; Dubruel, P.; Leys, C.; Payen, E. Stability study of polyacrylic acid films plasma-polymerized on polypropylene substrates at medium pressure. Appl. Surf. Sci. 2010, 257, 372-380. [CrossRef]

19. Geyter, N.D.; Morent, R.; Vlierberghe, S.V.; Dubruel, P.; Leys, C.; Gengembre, L.; Schacht, E.; Payen, E. Deposition of polymethyl methacrylate on polypropylene substrates using an atmospheric pressure dielectric barrier discharge. Prog. Org. Coat. 2009, 64, 230-237. [CrossRef]

20. Geyter, N.D.; Morent, R.; Leys, C.; Gengembre, L.; Payen, E. Treatment of polymer films with a dielectric barrier discharge in air, helium and argon at medium pressure. Surf. Coat. Technol. 2007, 201, 7066-7075. [CrossRef]

21. Casserly, T.B.; Gleason, K.K. Effect of substrate temperature on the plasma polymerization of poly(methyl methacrylate). Chem. Vap. Depos. 2006, 12, 59-66. [CrossRef]

22. Kasih, T.P.; Kuroda, S.-I.; Kubota, H. Poly(methyl methacrylate) films deposited via non-equilibrium atmospheric pressure plasma polymerization using argon as working gas. Plasma Process. Polym. 2007, 4, 648-653. [CrossRef]

23. Vrekhem, S.V.; Morent, R.; Geyter, N.D. Deposition of a PMMA coating with an atmospheric pressure plasma jet. J. Coat. Technol. Res. 2018, 15, 679-690. [CrossRef]

24. Cools, P.; Geyter, N.D.; Vanderleyden, E.; Barberis, F.; Dubruel, P.; Morent, R. Adhesion improvement at the PMMA bone cement-titanium implant interface using methyl methacrylate atmospheric pressure plasma polymerization. Surf. Coat. Technol. 2016, 294, 201-209. [CrossRef]

25. Vrekhem, S.V.; Vloebergh, K.; Asadian, M.; Vercruysse, C.; Declercq, H.; Tongel, A.V.; Wilde, L.D.; Geyter, N.D.; Morent, R. Improving the surface properties of an UHMWPE shoulder implant with an atmospheric pressure plasma jet. Sci. Rep. 2018, 8, 4720. [CrossRef] [PubMed]

26. Park, C.-S.; Kim, D.H.; Shin, B.J.; Tae, H.-S. Synthesis and characterization of nanofibrous polyaniline thin film prepared by novel atmospheric pressure plasma polymerization technique. Materials 2016, 9, 39. [CrossRef] [PubMed]

27. Park, C.-S.; Jung, E.Y.; Kim, D.H.; Kim, D.Y.; Lee, H.-K.; Shin, B.J.; Lee, D.H.; Tae, H.-S. Atmospheric pressure plasma polymerization synthesis and characterization of polyaniline films doped with and without iodine. Materials 2017, 10, 1272. [CrossRef] [PubMed]

28. Park, C.-S.; Kim, D.Y.; Kim, D.H.; Lee, H.-K.; Shin, B.J.; Tae, H.-S. Humidity-independent conducting polyaniline films synthesized using advanced atmospheric pressure plasma polymerization with in-situ iodine doping. Appl. Phys. Lett. 2017, 110, 033502. [CrossRef]

29. Kim, D.H.; Park, C.-S.; Kim, W.H.; Shin, B.J.; Hong, J.G.; Park, T.S.; Seo, J.H.; Tae, H.-S. Influences of guide-tube and bluff-body on advanced atmospheric pressure plasma source for single-crystalline polymer nanoparticle synthesis at low temperature. Phys. Plasmas 2017, 24, 023506. [CrossRef]

30. Park, C.-S.; Jung, E.Y.; Kim, D.H.; Cho, B.-G.; Shin, B.J.; Tae, H.-S. TOF-SIMS study on nano size conducting polymer prepared by simple atmospheric pressure plasma polymerization technique for display applications. Mol. Cryst. Liq. Cryst. 2017, 651, 16-25. [CrossRef]

31. Phan, L.T.; Yoon, S.M.; Moon, M.-W. Plasma-based nanostructuring of polymers: A Review. Polymers 2017, 9, 417. [CrossRef]

32. Lv, S.; Zhao, X.; Shi, L.; Zhang, G.; Wang, S.; Kang, W.; Zhuang, X. Preparation and properties of sc-PLA/PMMA transparent nanofiber air filter. Polymers 2018, 10, 996. [CrossRef]

33. Ting, Y.-H.; Liu, C.-C.; Park, S.-M.; Jiang, H.; Nealey, P.F.; Wendt, A.E. Surface roughening of polystyrene and poly(methyl methacrylate) in Ar/O 2 plasma etching. Polymers 2010, 2, 649-663. [CrossRef]

34. Buruaga, L.; Pomposo, J.A. Metal-free polymethyl methacrylate (PMMA) nanoparticles by enamine "Click" chemistry at room temperature. Polymers 2011, 3, 1673-1683. [CrossRef]

35. Burrows, P.E.; Graff, G.L.; Gross, M.E.; Martin, P.M.; Shi, M.K.; Hall, M.; Mast, E.; Bonham, C.; Bennett, W.; Sullivan, M.B. Ultra barrier flexible substrates for flat panel displays. Display 2001, 22, 65-69. [CrossRef]

36. Yamashita, K.; Mori, T.; Mizutani, T. Encapsulation of organic light-emitting diode using thermal chemical-vapour-deposition polymer film. J. Phys. D 2001, 34, 740-743. [CrossRef]

37. Alghunaim, N.S. Spectroscopic analysis of PMMA/PVC blends containing $\mathrm{CoCl}_{2}$. Results Phys. 2015, 5, 331-336. [CrossRef]

38. Jasim, R.I.; Jameel, A.N.; Alwan, T.J. Synthesis and characterization the optical properties and FT-IR spectroscopy of PMMA/CR $\mathrm{O}_{3}$ blend films. GESJ Phys. 2016, 1, 45-53. 
39. Thakur, V.K.; Vennerberg, D.; Madbouly, S.A.; Kessler, M.R. Bio-inspired green surface functionalization of PMMA for multifunctional capacitors. RSC Adv. 2014, 4, 6677-6684. [CrossRef]

40. Vijayakumari, G.; Selvakumar, N.; Jeyasubramanian, K.; Mala, R. Investigation on the electrical properties of polymer metal nanocomposites for physiological sensing applications. Phys. Proc. 2013, 49, 67-78. [CrossRef]

41. Ma, Y.; Cao, X.; Feng, X.; Ma, Y.; Zou, H. Fabrication of super-hydrophobic film from PMMA with intrinsic water contact angle below $90^{\circ}$. Polymer 2007, 48, 7455-7460. [CrossRef]

42. Raptis, I.; Kovač, J.; Chatzichristidi, M.; Sarantopoulou, E.; Kollia, Z.; Kobe, S.; Cefalas, A.C. Enhancement of sensing properties of thin poly(methyl methacrylate) films by VUV modification. J. Laser Micro/Nanoeng. 2007, 2, 200-205. [CrossRef]

43. Naderi-Gohar, S.; Huang, K.M.H.; Wu, Y.; Lau, W.M.; Nie, H.-Y. Depth profiling cross-linked poly(methyl methacrylate) films: a time-of-flight secondary ion mass spectrometry approach. Rapid Commun. Mass Spect. 2017, 31, 381-388. [CrossRef] [PubMed]

44. Mahoney, C.M.; Fahey, A.J.; Gillen, G. Temperature-controlled depth profiling of poly(methyl methacrylate) using cluster secondary ion mass spectrometry. 1. Investigation of depth profile characteristics. Anal. Chem. 2007, 79, 828-836. [CrossRef]

45. Dekeyser, C.M.; Biltresse, S.; Marchand-Brynaert, J.; Rouxhet, P.G.; Dupont-Gillain, C.C. Submicrometer-scale heterogeneous surfaces by PS-PMMA demixing. Polymer 2004, 45, 2211-2219. [CrossRef]

46. Endo, K.; Kobayashi, N.; Aida, M.; Hoshi, T. Spectral analysis of polystyrene, polypropylene, and poly(methyl methacrylate) polymers in TOF SIMS and XPS by MO calculations using the model oligomers. Polym. J. 1996, 28, 901-910. [CrossRef]

47. Sathish, S.; Chandar, S.B. Dip and spin coated nanoscale transparent PMMA thin films for field effect thin film transistors and optoelectronic devices. J. Optoelectron. Adv. Mater. 2013, 15, 139-144.

48. Sathish, S.; Chandar, S.B. Preparation and characterization of nano scale PMMA thin films. Ind. J. Pure Appl. Phys. 2014, 52, 64-67.

49. Wang, B.; Lin, Q.; Shen, C.; Han, Y.; Tang, J.; Chen, H. Synthesis of MA POSS-PMMA as an intraocular lens material with high light transmittance and good cytocompatibility. RSC Adv. 2014, 4, 52959-52966. [CrossRef]

50. Choi, B.K.; Lee, I.H.; Kim, J.H.; Chang, Y.J. Tunable wetting property in growth mode-controlled WS 2 thin films. Nanoscale Res. Lett. 2017, 12, 262. [CrossRef] [PubMed]

51. Ahmad, J.; Bazaka, K.; Oelgemöller, M.; Jacob, M.V. Wetting, solubility and chemical characteristics of plasma-polymerized 1-isopropyl-4-methyl-1,4-cyclohexadiene thin films. Coatings 2014, 4, 527-552. [CrossRef]

52. Patel, K.H.; Rawal, S.K. Exploration of wettability and optical aspects of ZnO nano thin films synthesized by radio frequency magnetron sputtering. Nanomater. Nanotechnol. 2016, 6, 22. [CrossRef] 